\title{
БУХГАЛТЕРСКИЙ УЧЕТ И КОНТРОЛЛИНГ В ХОЗЯЙСТВЕННОЙ ДЕЯТЕЛЬНОСТИ ЭКОНОМИЧЕСКОГО СУБЪЕКТА
}

\author{
(c) 2021 Шлычков Дмитрий Сергеевич \\ доцент департамента аудита и корпоративной отчетности \\ Финансовый университет при Правительства Российской Федерации, Россия, Москва \\ E-mail: sds457@mail.ru
}

В статье исследуется вопрос организации бухгалтерского учета и контроллинга в системе экономического субъекта и их взаимосвязь, и взаимозависимость. Определяются возможные факторы (внешние и внутренние), влияющие на деятельность экономического субъекта, а также пути снижения различных бизнес-рисков с помощью внедрения модели контроллинга с использованием данных системы бухгалтерского учета.

Ключевые слова: экономический субъект, бухгалтерский учет, контроллинг.

Современные условия бизнес-среды претерпевают значительные изменения в условиях финансово-хозяйственной деятельности. Основным внешнем фактором, влияющим на изменения хозяйствования, является система государственного регулирования бизнеса.

Государственная политика в настоящее время направлена на социальное обеспечение граждан и удержание среднего класса населения в рамках, не выпадающих за черту бедности. В этой связи государству необходимо обеспечить население достойным образованием, медицинским обслуживанием, жилищными условиями и другим жизненно минимальным перечнем услуг необходимых для жизни. В связи с этим, для реализации государственных программ необходимы финансовые средства, которые поступают в бюджет в виде налогов, уплачиваемых экономическим субъектом.

Экономический субъект - это организационно-правовая, финансовая и производственная структура, созданная для ведения хозяйственной деятельности определенным кругом лиц(а), направленная на удовлетворение потребностей групп обществ с целью получения экономических выгод.

Роль экономического субъекта в жизни государства велико. Как было определено выше создание продукта экономическим субъектом и его последующая реализация потребителям данного продукта приводит к увеличению как собственного капитала, так и к взаимосвязям с государством посредством уплаты налогов. В этой связи необходимо говорить о создании определенного баланса взаимоотношений между экономическим субъектом и государством в лице государственных органов (налоговой службы, различными министерствами и ведомствами).

При ведении финансово-хозяйственной деятельности экономический субъект подвержен не только внешним, но и внутренним рискам. Внешние риски можно разделить на две категории:

1) государственный риск - к нему можно отнести государственное регулирование бизнеса через законодательные акты, создание не приемлемых условий хозяйствования посредством различных ограничений и другие риски административного воздействия;

2) риск недобросовестного партнера - это риск, идущий от контрагентов, с которыми имеются договорные обязательства. Данный риск связан не только с поставками ресурсов для производства продукции, но и риск финансовой составляющей, например, через налоговые платежи (недобросовестное декларирование налогов), а также риск получения статуса «недобросовестного налогоплательщика» (рис. 1).

Внутренние риски - риски, созданные внутри экономического субъекта через его сотрудников. К таким рискам можно отнести:

- репутационный риск,

- риск деловой активности,

- учетно-аналитический риск,

- риск контроля,

- риск экономической безопасности,

- другие риски, влияющие на финансовую и 
Внешние фракторы, влияющие на деятельность экономического субъекта

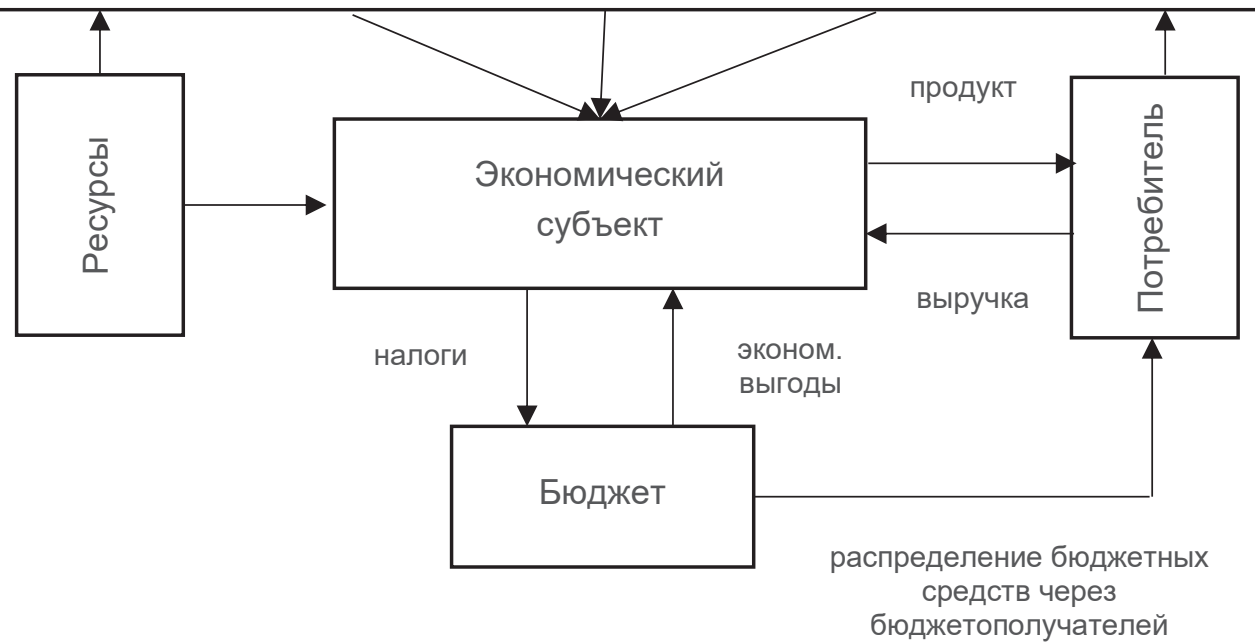

Рuc. 1. Экономический субъект в системе государственного регулирования.

производственную деятельность.

В целях реализации стратегии деятельности экономического субъекта и минимизации влияния различных негативных факторов на финансово-хозяйственную деятельность и предотвращение последствий различных рисков необходима разработка учетно-контрольный системы экономической безопасности.

Учетно-контрольная система экономической безопасности - это взаимодействие между собой системы бухгалтерского учета и системы контроллинга, выполняющих функцию экономической безопасности экономического субъекта.

Основополагающей системой для учета и контроля хозяйственных операций экономического субъекта является бухгалтерский учет. Согласно федеральному закону № 402-Ф3
«О бухгалтерском учете» руководитель экономического субъекта обязан организовать систему бухгалтерского учета таким образом, чтобы она отражала требования и допущения, закрепленные ПБУ 1/2008. Сама система бухгалтерского учета - это организация движения информационных потоков у экономического субъекта. Основываясь на определении бухгалтерского учета - формирование документированной систематизированной информации об объектах, в соответствии с требованиями, установленными законом о бухгалтерском учете, и составление на ее основе бухгалтерской (финансовой) отчетности [закон], определяется классический бизнес-процесс системы бухгалтерского учета на основе его методов (рис. 2).

Необходимо обратить внимание на то, что Приказом Минфина России от 16.04.2021 № 62н

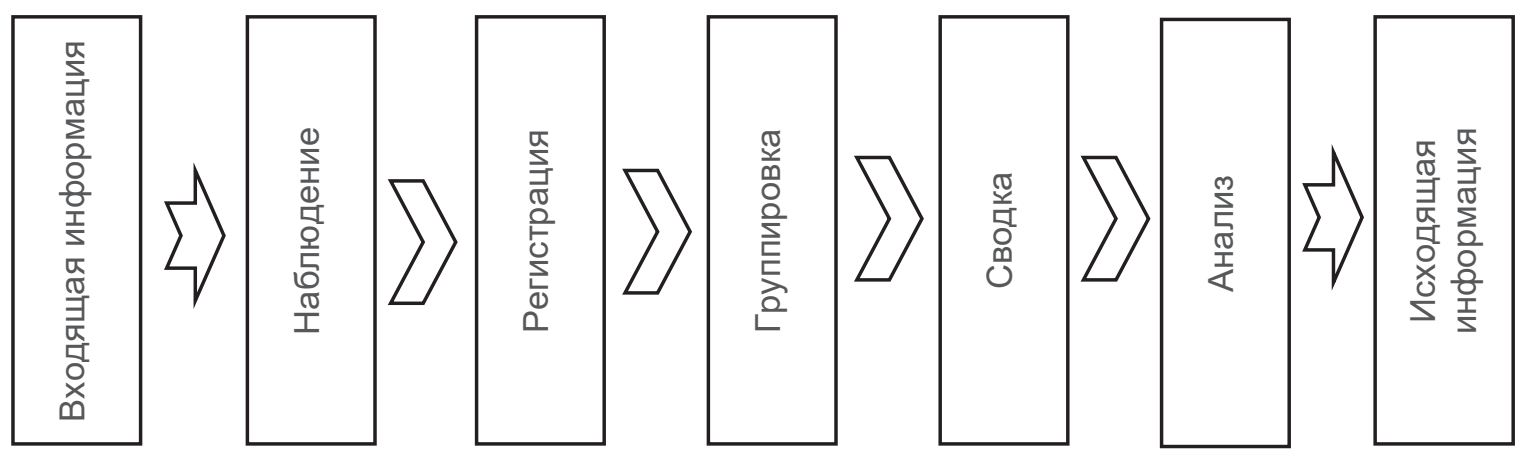

Puc. 2. Бизнес-процесс обработки информации в бухгалтерском учете [4] 
утвержден Федеральный стандарт бухгалтерского учета (ФСБУ) 27/2021 «Документы и документооборот в бухгалтерском учете», который с 01 января 2022 г. обязателен для применения экономическим субъектом.

Несмотря на то, что входящая информация может поступать различными способами, однако подтверждением хозяйственных сделок является первичный документ, который может быть в виде электронного документа, подписанного усиленной цифровой подписью или на бумажном носителе. На любом этапе обработки первичной информации, отраженной на рисунке 2 , можно в определенной степени осуществлять контроль за движением входящей информации.

В силу того, что система бухгалтерского учета не дает достаточно полного контроля над всеми протекающими финансово-хозяйственными операциями у экономического субъекта требуется с учетом действующей системы бухгалтерского учета построить такую систему, которая позволит давать управленцам стратегически важную информацию и жесткий контроль над протекающими операциями. В современных условиях хозяйствования для реализации требований, предъявляемых к управлению экономическим субъектом и взаимодействию со многими экономическими сферами в том числе контролем за внешними и внутренними рисками, позволяет реализовать система контроллинга.

Контроллинг - это интегрированная система информационно-аналитической и методической поддержки руководителей в процессе планирования, контроля, анализа и принятия управленческих решений по всем функциональным сферам деятельности предприятия.

Цель контроллинга состоит в реализации разделения имеющихся единых методов, их проверке на эффективность управления организацией, а также их доработку и объединение в единую систему. Важнейшими составными методами системы управления, на которые ориентируется работа менеджера-контроллера, являются методы планирования и контроля и процессы информационного обеспечения, что составляет концепцию контроллинга (рис. 3).

Система контроллинга основывается на таких методах управления финансовохозяйственной деятельности экономического субъекта как прогнозирование, планирование, бюджетирование, контроль и анализ.

Таким образом система контроллинга охватывает широкий спектр управленческих решений - это система стратегического мышления и действий менеджмента экономического субъекта.

При реализации системы контроллинга в организации необходимо создавать новую структуру со штатом контроллеров, а не передавать полномочия на действующий штат бухгалтеров и экономистов. Данная структура организации не будет носить функции ревизоров или внутренних аудиторов, а функции контроллеров - управление административными и производственными процессами для достижения стратегической цели или миссии экономического субъекта. В этой связи необходимо построение параллельно двух систем бухгалтерского учета и контроллинга и их взаимоотношение между собой без определенных вмешательств в деятельность друг друга (рис. 4).

Подводя итог, можно сказать, что система бухгалтерского учета и система контроллинга дополняют друг друга, что показано на рисунке 4. Пунктирные линии показывают, что потоки информации, обрабатывающиеся в системе бухгалтерского учета необходимы для построения потоков информации в системе контроллинга. Нельзя допускать чтобы сотрудники того или иного подразделения вмешивались в деятельность друг друга, что может нарушить определенные цели и задачи достижения стратегической миссии экономического субъекта. Кроме того, наблюдая развитие цифровизации экономических процессов, обобщать в единую систему информационных потоков бухгалтерский учет и контроллинг не целесообразно, так как системы направлены на различные функциональные цели деятельности. 


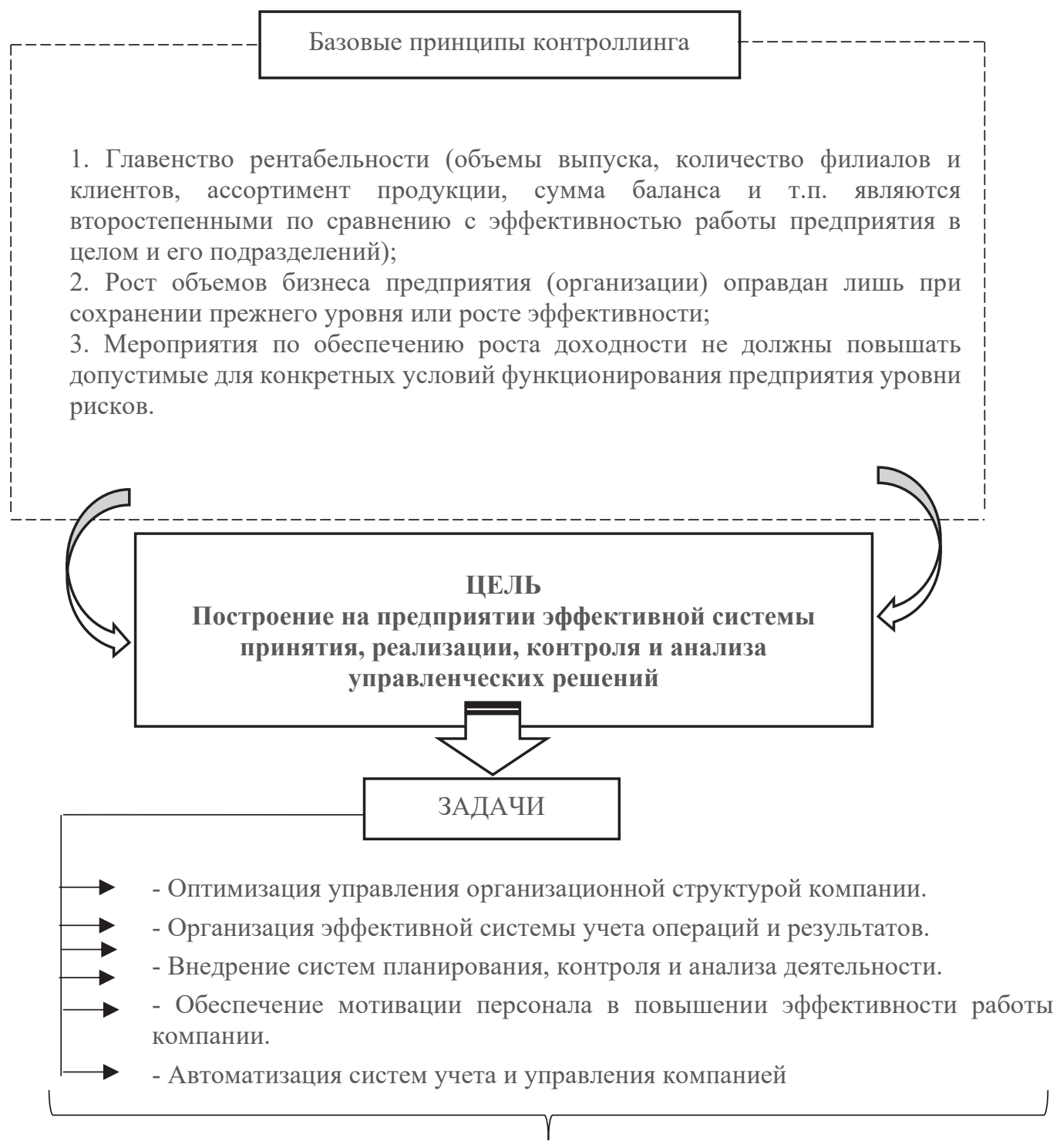

Результат от внедрения

Получить четкую систему прогнозирования и планирования деятельности предприятий. Своевременно получать точную и достаточную информацию с предприятий, необходимую для принятия обоснованных управленческих решений.

Иметь инструмент воздействия на предприятия в процессе выполнения плана, гарантирующий выполнение планов.

Постепенно повышать эффективность деятельности предприятий, повышать рентабельности инвестиций.

Изменить психологию руководителей предприятий, ориентировать их на экономические и финансовые показатели в работе предприятий

Puc. 3. Концепция контроллинга [8] 


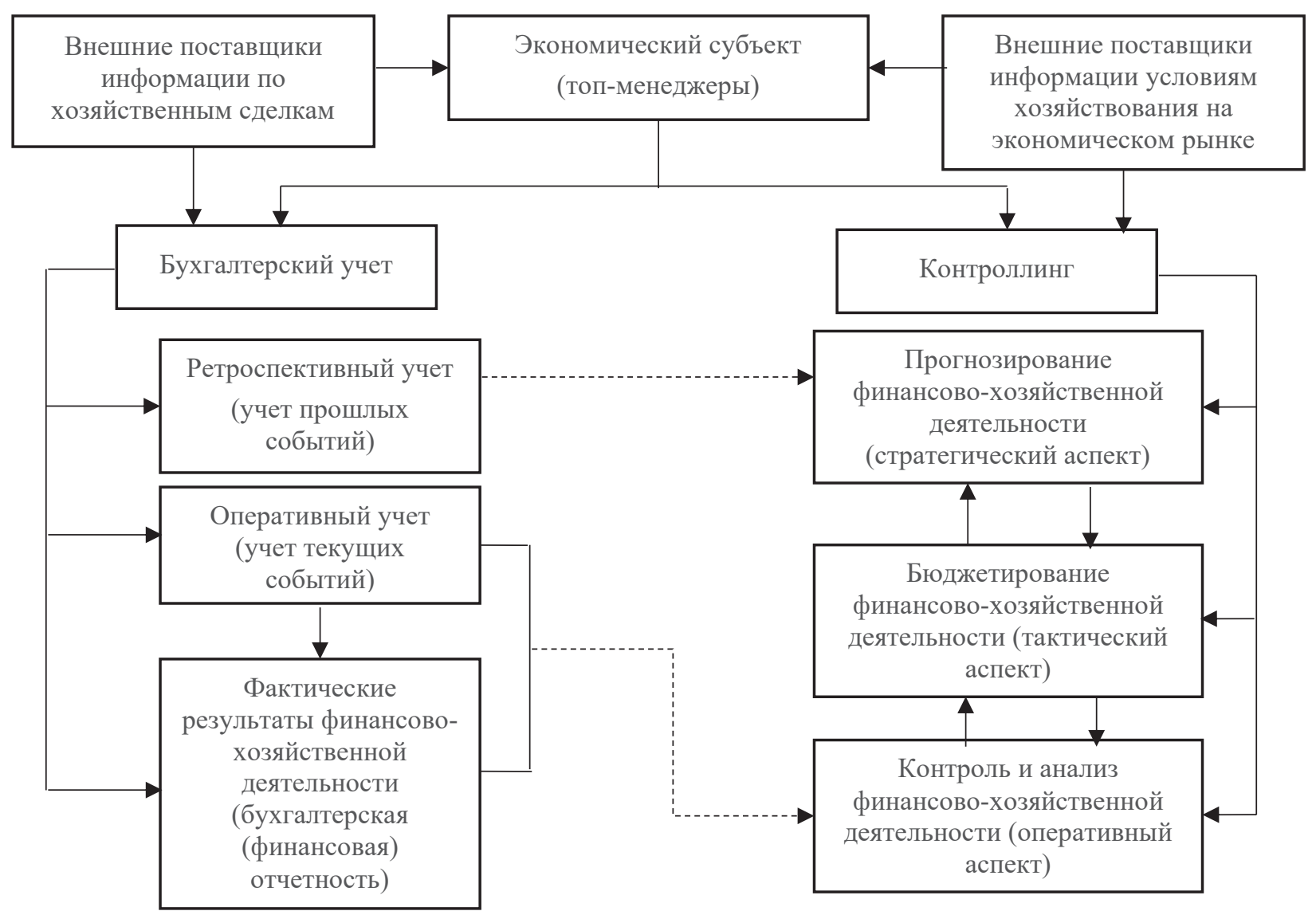

Рис. 4. Взаимосвязь бухгалтерского учета и контроллинга.

\section{Библиографический список}

1. Федеральный закон «О бухгалтерском учете» от 06.12.2011 № 402-Ф3

2. Анализ финансовых рисков и формирование резервов. Монография / Мельникова Л. А., Петров А. М. - Москва: ООО «Издательство «Спутник+», 2020. - 299 с.

3. Андреев Р.Н. Экономическая сущность и принципы бюджетирования / Современные тенденции развития науки и технологий. 2018. № 3-11 (24). С. 36-38.

4. Бухгалтерский учет: учебно-практическое пособие для бакалавров направления подготовки «Экономика» / Д.С.Шлычков. - Москва: РУСАЙНС, 2019. - 160 с.

5. Кренева С.Г., Терёшина В.В. Регулирование бизнес-процессов организаций для обеспечения их экономической безопасности // Инновационное развитие экономики. - 2020. - № 6 (60). С. 377-382.

6. Ладыгин В.В. Бюджетирование и контроль на предприятии. - М.: ЛЕНАНД, 2020. - 530 с. // [Электронный pecypc] URL: http://urss.ru/253247

7. Настольная книга финансового директора / Стивен М.Брег; Пер. с англ. - 3-е изд. - М.: Альпина Бизнес Букс, 2066. -536 с.

8. Организация налогового планирования и бюджетирования: учебное пособие / М. С. Шемякина, Д. С. Шлычков. - Москва: КНОРУС, 2021. - 222 с. - (Бакалавриат и магистратура) 